\title{
UNA NUEVA ESPECIE DE AYENIA (STERCULIACEAE) DE MINAS GERAIS (BRASIL)
}

\author{
CARMEN L. CRISTÓBAL
}

\begin{abstract}
Summary: Cristobal, C.L. 2003. A new species of Ayenia (Sterculiaceae) from Minas Gerais (Brasil). Bonplandia 12: 153-156. ISSN: 0524-0476.

Ayenia nervosa Cristobal, a new species from Brasil, Minas Gerais, is described and illustrated. It is placed in the section Ayenia subsection Ayenia. Photomicrographs of the abaxial face of the leaf, showing the peculiar type of hairs, are also included.
\end{abstract}

Key words: Ayenia, Sterculiaceae, taxonomy, Minas Gerais.

Resumen: Cristóbal, C.L. 2003. Una nueva especie de Ayenia (Sterculiaceae) de Minas Gerais (Brasil). Bonplandia 12: 153-156. ISSN: 0524-0476.

Ayenia nervosa Cristóbal, una nueva especie de Brasil, Minas Gerais, es descripta e ilustrada. Pertenece a la sección Ayenia subsección Ayenia. Se discuten las diferencias entre la nueva especie y $A$. praecipua Cristóbal y $A$. angustifolia A. St.-Hil. \& Naudin, consideradas afines. Fotomicrografías del hipofilo de $A$. angustifolia $y$ de la especie nueva mostrando el tipo distintivo de pelos son también incluidas.

Palabras clave: Ayenia, Sterculiaceae, taxonomía, Minas Gerais.

Ayenia nervosa Cristóbal sp. nov.

Figs. 1-2-A-C

Suffrutex ramis $25-35 \mathrm{~cm}$ altis, 2-3 $\mathrm{mm}$ diam. dense foliatis. Folla supra subtusque conspicue nervosa, anguste lanceolata, acuta, 1,5-2,8 cm longa $x$ 0,27-0,4 cm lata, supra et subtus pilis planis sparcis (1-) 2-4 (-5) ramis antrorsis et adpresis. Flores congestis in cymis axillaribus brevibus, multifloribus. Pedicelli, sepalo et petalo purpurei.

Holotypus: BRASIL. Minas Gerais: Virgem da Lapa. Calha do rio sobre afloramento. Maio, [16²8'42²0'], 1997. E. Tameirao Neto 2518 (BHCB 45510), isotypus CTES.

Subarbusto de 25-35 cm alt., erecto, base persistente, leñosa hasta $5 \mathrm{~mm}$ diám., ramas floríferas con el tallo de 2-3 mm diám., densamente hojosas, entrenudos de $3-5 \mathrm{~mm}$ iong., con pelos que dejan ver la superficie de la epidermis, simples y entre ellos otros con 2-4 ramas, todos acroscópicos y adpresos, porción basal de las ramas desnuda, leñosa, cicatricosa, los nudos se destacan por las cicatrices de las inflorescencias que forman conjuntos de ca-

Instituto de Botánica del Nordeste, Casilla de Correo 209, 3400 Corrientes, Rep. Argentina. Correo electrónico: ibone@agr.unne.edu.ar 
BONPLANDIA 12(1-4). 2003

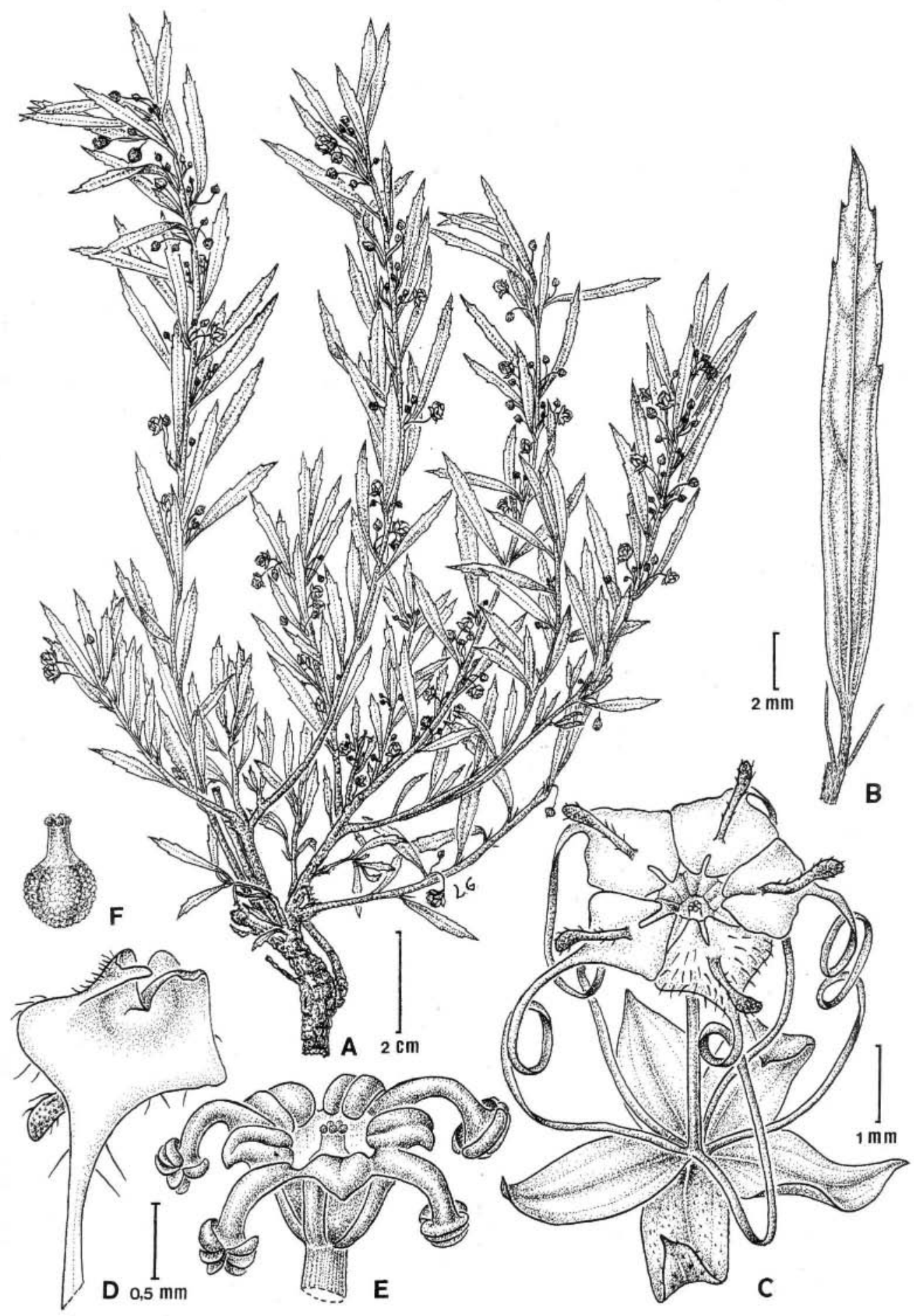

Fig. X.Ayenia nervosa. A: planta. B: hoja .C: flor completa. D: cara interna de la capucha de la uña de un pètalo. E: tubo estaminal. F: gineceo. Todo del paratipo. 

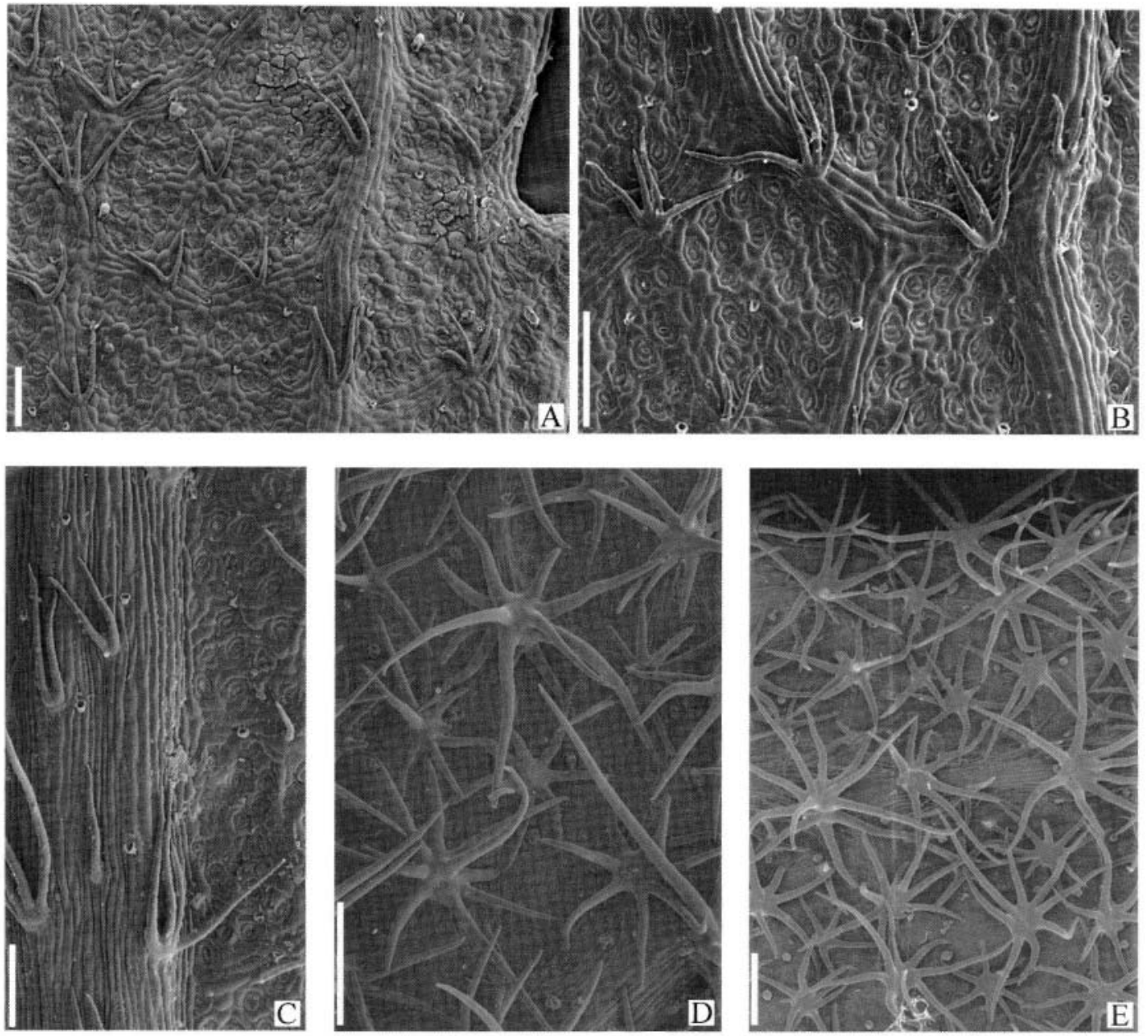

Fig. 2. Fotomicrografías del hipofilo. A-C: Ayenia no-vosa, paratipo. D-E: A. angustifolia, Irwin \& al. 27018 (CTES).

líos abultados, lustrosos y negros como la corteza que es marcadamente estriada. Estípulas lineares, $3 \mathrm{~mm}$ long., con escasos pelos dispersos. Pecíolo subterete, 1,5-2 mm long., con el mismo indumento que el tallo. Lámina angostamente lanceolada, aguda, 1,5-2,8 cm long. x 2,7-4 mm lat., venación mayor y menor igualmente sobresaliente en ambas caras, desde la base un par de venas secundarias paralelas a la vena media por un brevísimo trecho y un segundo par marginal muy corto, margen dentado, entero en aproximadamente los $2 / 3$ proximales, dientes distantes y poco profundos con el ápice redondeado y oscuro, en las hojas jóvenes terminados en una seta, pelos simples y con 2-4 brazos acroscópicos, más o menos aplastados, dispersos en el epifilo e hipofilo especialmente sobre las ve- nas, hojas básales glabrescentes. Flores reunidas en cimas axilares multifloras, abreviadas, en cada nudo se aglomeran 4 o más fascículos 3-5-floros, cada uno rodeado de bractéolas amarillentas, membranáceas. Pedicelos 7-9 mm long., purpúreos, pelos dispersos simples y con 2-3 ramas como los del tallo pero no adpresos. Cáliz membranáceo, púrpura intenso, sépalos oblongos, 2,5 mm long. x $1,5 \mathrm{~mm}$ lat., trinervados, cara externa con pelos dispersos como los del pedicelo, cara interna con la vena media sobresaliente y pelos capitados diminutos en toda la superficie. Pétalos largamente unguiculados, purpúreos, porción basal de la uña filiforme, 5-6,5 mm long., porción distal (capucha) romboidal, $1,2 \mathrm{~mm}$ long. $\mathrm{x}$ 1,5 mm lat., escotada en el ápice y allí adosada al borde del tubo estaminal, cara externa con 
pelos glandulares largos dispersos, cara interna con un diente a cada lado de la línea media y entre ellos un canal donde se acomoda la porción libre de filamento estaminal; lámina del pétalo reducida a un apéndice inserto en la mitad de la porción romboidal de la uña tan largo que sobresale del margen distal de la misma, linear en los $2 / 3$ básales, glandular, púrpura y abultado en el extremo, pequeños pelos dispersos en todo su largo. Androginóforo 3-3,5 mm long. Tubo estaminal urceolado 1,3 mm long., con 5 venas sobresalientes, estambres con una porción libre de filamento, anteras tritecas, estaminodios alternipétalos, cuculados, recurvados, con el margen externo redondeado. Gineceo incluido en el tubo estaminal, estilo breve, estigma 5-lobulado. Fruto no visto.

Paratipo: BRASIL. Minas Gerais: Berilo (próximo ao povoado de Lelivéldia). [16 $6^{\circ} 58^{\prime} 42^{\circ}$ 28']. Mata ciliar rio Jequitinhonha. 24.IV. 1991. M.G. Carvalho \& S.T. Silva 186 (BHCB).

Ayenia nervosa pertenece a la sección Ayenia y dentro de ella al grupo de especies que poseen las hojas con la venación sobresaliente en ambas caras. A este grupo pertenecen, entre otras, A. latifolia Cristóbal, A. praecipua Cristóbal y A. angustifolia A. St.Hil. \& Naudin, siendo las dos últimas las más cercanas a la novedad aquí presentada, por tener hojas alargadas, pero en $A$. nervosa son muy angostas y agudas. De ambas se diferencia además por la calidad del indumento, ya que estas especies presentan hojas con pelos estrellados. Ayenia nervosa, en cambio tiene pelos muy particulares, constituidos por (1-) 2-4 (-5) brazos unicelulares acroscópicos y dispuestos en un solo plano (Fig. 2). Estos pelos se encuentran dispersos sobre las venas y son más abundantes en el hipofilo de las hojas jóvenes. Los pelos de las dos especies afines mencionadas son estrellados, es decir con brazos que se disponen en todas direcciones y en distintos planos. En el caso de $A$. angustifolia la base de las células que conforman estos pelos se eleva algo por sobre la superficie de la epidermis de manera que el pelo tiene un pequeño pie.

Ayenia praecipua vive en Brasil en los estados de São Paulo y Mato Grosso do Sul, Paraguay oriental y en el Nordeste de Argentina. Tiene las hojas oval-lanceoladas u obovadas, dentadas desde la base y los nudos floríferos son 1-3-floros, los pedicelos son de ca. $3 \mathrm{~mm}$ long., casi del mismo largo que el androginóforo, y el cáliz y los pedicelos son amarillentos.

Ayenia angustifolia es una especie brasileña de amplia distribución, su área abarca $\mathrm{S}$ de Maranháo, Bahia, Minas Gerais, Tocantins, Distrito Federal, Goiás hasta el SE de Mato Grosso donde vive en el cerrado y en los campos rupestres. Son plantas de mayor porte 0,50-1 m alt. y más robustas que las de $A$. nervosa, el tallo en la base puede llegar hasta $8 \mathrm{~mm}$ diám., las hojas son muy coriáceas, y densamente cubiertas de pelos estrellados gruesos, amarillentos (Fig 2, D-E).

Ayenia angustifolia y A. latifolia Cristóbal, especie esta última de Bahia y Goiás, tienen la particularidad de poseer flores morfológicamente perfectas pero funcionalmente diclino-dioicas (Cristóbal, 1960, 1997). Hay que prestar atención al material de futuros hallazgos de $A$. nervosa, ya que existe la posibilidad de que en esta nueva especie se presenten también dos tipos de ñores. Los ejemplares mencionados en este trabajo fueron herborizados en marzo y en mayo, en plena floración. Los nudos están congestionados de flores en distinto estado de desarrollo, pero no he observado en las flores marchitas estados iniciales de desarrollo del fruto, como es habitual en estos casos, lo que hace pensar que pueden tratarse de flores funcionalmente masculinas.

\section{Bibliografía}

CRISTÓBAL, C. L., 1960. Revisión del género Ayenia (Sterculiaceae). Opera Lilloana 4:1-230. 79 figs.

1997. Dos Esterculiáceas Sudamericanas nuevas. Bonplandia 9(3-4): 213-218, 2 figs.

Original recibido el 14 de mayo de 2003; aceptado el 27 de julio de 2003. 